\title{
Mentoring In The Clinical Setting To Improve Student Decision-Making Competence
}

\author{
Misty Stick-Mueller DC, Palmer College of Chiropractic, USA \\ Ron Boesch DC, Palmer College of Chiropractic, USA \\ Steven Silverman DC, Palmer College of Chiropractic, USA \\ Scott Carpenter DC, Palmer College of Chiropractic, USA \\ Robert Illingworth DC, Palmer College of Chiropractic, USA \\ James Countryman DC, Palmer College of Chiropractic, USA
}

\begin{abstract}
Introduction: The physician-intern relationship can be difficult to develop. A new chiropractic intern in a teaching clinic undergoes a major transition from classroom to clinical practice and must learn to turn classroom knowledge into clinical application. The ability to start formulating clinical techniques and apply them on a patient is daunting. Developing a mentor relationship is difficult to do in a patient-care setting, but it can be done. Mentoring is a process of exchanging skills and values between 2 individuals with the goal of increasing the knowledge base and clinical skills of the intern. With this in mind, our group created short-duration small-group mentoring classes offered at different times on multiple days, permitting interns to have numerous opportunities to view procedure and ask questions about the topic of that day's presentation.

Methods: This project spanned a period of 3 months, during which time 6 clinicians were in charge of educating approximately 50 students. The mentorship model was developed so that in addition to the clinicians' regular duties of supervising patient care with interns, there would also be 3 15-minute sessions per week presenting a topic of a clinician's choice pertinent to the intern learning experience.

Results: 209 evaluations were turned in, with 5 students not completing the evaluation. Students overwhelmingly believed that these sessions were beneficial to their learning and provided them with the opportunity to ask questions in regard to the topics.

Conclusion: Students agreed that these small group mentoring sessions provided them with more information than they previously had learned in the classroom. They thought that the sessions gave them enough information to be motivated to use the knowledge they learned from the session to make decisions on the topic when faced with a patient with a similar problem. This is a small survey sample that will need further review and trials to determine if it will provide the necessary feedback to help improve small group presentations. It will also need to be spread to other clinical settings to determine if it is beneficial for this style of small groups to aid other learners and to evaluate its helpfulness to interns in putting clinical information and evaluations together for practice. Follow-up studies could also include evaluating students at a later date to determine if the students are using the information that they are learning from the sessions.
\end{abstract}

Keywords: Mentoring, Student Competence

\section{INTRODUCTION}

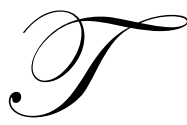

he physician-intern relationship can be difficult to develop. A new chiropractic intern in a teaching clinic undergoes a major transition from classroom to clinical practice and must learn to turn classroom knowledge into clinical application. The ability to start formulating clinical techniques and apply them on a patient is daunting. Oftentimes, the intern will witness the clinician's bedside manner and gain 
knowledge from the case he or she is attending, but the reasoning behind that clinician's decisions may be unclear to the intern. Interns may wish to gain greater understanding of the reasoning processes (the clinical heuristic) behind the doctor's thinking, but time constraints and patient loads may restrict the opportunity for an intern to ask questions of the clinician.

\section{BACKGROUND}

Developing a mentor relationship is difficult to do in a patient-care setting, but it can be done. Mentoring is a process of exchanging skills and values between 2 individuals with the goal of increasing the knowledge base and clinical skills of the intern. Conley (2001) defines mentoring as "the act of supporting the learning process of a "junior" or less skilled member of a community of practice utilizing a variety of behaviors to enhance the learning process." In a mentoring relationship, one individual has the expertise which the other individual is striving to learn and a relationship develops between the 2 to enhance the intern's understanding of clinical knowledge and expertise. With this in mind, our group created short-duration small-group mentoring classes offered at different times on multiple days, permitting interns to have numerous opportunities to view procedure and ask questions about the topic of that day's presentation.

We briefly reviewed literature relevant to mentoring a physician-intern relationship. Our search was conducted through the EBSCOhost search engine.

Marx (2006) reviewed the College of Healthcare Information Management Executives CIO Boot Camp program. In this program, students who are weak in a certain area, such as clinical background, are paired with wellrespected clinicians with strong clinical backgrounds. Clinicians in this situation not only mentor others, but also have their own mentors. The determination of the purpose of the mentoring program here is "to allow the student to get an inside look at the mentor's daily routine and learn to navigate the organization to facilitate success." It was found that mentors also gained from the relationship, providing a "win-win" situation.

Kim (2007) proposed that mentors with higher learning goal orientation are able to offer more challenging assignments, greater leadership and better student counseling than mentors lacking these skills, whereas interns with this same orientation will get more out of the training than those lacking such an orientation. Both the mentor and the student will enhance his or her leadership skills as a significant outcome of this relationship.

Conley (2001) studied the behaviors of interpersonal relationships between the mentor and student, career advancement possibilities, and the development of competence in the mentoring structure. This study found that competency development was the most common strategy used in the medical profession, leading to better skill performance and increased procedural and tacit knowledge. Students in the study felt that the development of expertise was dependent upon gaining these competency behaviors. Conley proposed that mentors' roles are to facilitate the "efficiency and efficacy of learning new skills and abilities... [to] promote connection of new information to existing knowledge."

\section{METHODS}

This project spanned a period of 3 months, during which time 6 clinicians were in charge of educating approximately 50 students. The mentorship model was developed so that in addition to the clinicians' regular duties of supervising patient care with interns, there would also be 315 -minute sessions per week presenting a topic of a clinician's choice pertinent to the intern learning experience. Topics included cervical, thoracic, lumbar or pelvic adjusting, headache, low back pain, and practice management. In each session, the clinician would cover the topic by providing examples of patient presentations and the clinical reasoning determining how to provide appropriate chiropractic care. Interns were provided with a schedule of talks to be presented over the course of the term. Adjusting suggestions and demonstrations were demonstrated where applicable, and interns had opportunity to question the clinician regarding details they either did not understand or that they wished to explore further. These sessions were not mandatory and interns had the option of attending any or all of the sessions offered during the week. Attendance was limited to approximately 10-12 interns per session to allow time for questions, but no one was ever turned away. At the conclusion of each session, interns had the option of responding to a survey that 
explored their understanding of the topic and their comfort level with the information that they had been given. Students would also provide data about whether they felt that these sessions provided them with information that was applicable to current or future patients. This study was deemed exempt from IRB review by the Palmer College of Chiropractic IRB.

\section{RESULTS}

A sample of the evaluation questions is noted below.

1. This presentation expanded on information I previously learned at (school).

2. This session enhanced my abilities to make decisions about the topic.

3. I am motivated to use the knowledge I gained at an upcoming patient visit.

4. I am more confident in my adjusting skills because of this session.

5. I enjoyed learning in this small group setting.

6. The presenter answered my questions effectively.

7. The presenter was effective in presenting this information.

Students were to respond on a 4-point scale using the following responses: Strongly Agree; Agree; Disagree; Strongly Disagree.

209 evaluations were turned in, with 5 students not completing the evaluation. The summary of results can be seen in table 1 .

Table 1: Summary of results

\begin{tabular}{|l|c|c|c|c|}
\hline & Strongly Agree & Agree & Disagree & Strongly Disagree \\
\hline Question 1 & $84.2 \%$ & $15.3 \%$ & $0 \%$ & $0.5 \%$ \\
\hline Question 2 & $89.5 \%$ & $10.5 \%$ & $0 \%$ & $0 \%$ \\
\hline Question 3 & $89.0 \%$ & $11.0 \%$ & $0 \%$ & $0 \%$ \\
\hline Question 4 & $83.6 \%$ & $15.5 \%$ & $0.9 \%$ & $0 \%$ \\
\hline Question 5 & $92.3 \%$ & $7.7 \%$ & $0 \%$ & $0 \%$ \\
\hline Question 6 & $92.8 \%$ & $7.2 \%$ & $0 \%$ & $0 \%$ \\
\hline Question 7 & $95.7 \%$ & $4.3 \%$ & $0 \%$ & $0 \%$ \\
\hline
\end{tabular}

Students overwhelmingly believed that these sessions were beneficial to their learning and provided them with the opportunity to ask questions in regard to the topics.

\section{CONCLUSION}

Students agreed that these small group mentoring sessions provided them with more information than they previously had learned in the classroom. They thought that the sessions gave them enough information to be motivated to use the knowledge they learned from the session to make decisions on the topic when faced with a patient with a similar problem. Students enjoyed the small group setting and believed that their questions were effectively answered. Student interns thought that the doctors were effective in presenting their information.

The question that rated the lowest of all was the increase in confidence in adjusting skills due to the session. It is believed that this rating would be increased with more time in the sessions for hands-on practice of the skills being presented; however increasing the time of the sessions may result in fewer students willing to attend the session.

The information gathered showed that the topics chosen by the doctors were beneficial to the learning of the students. Students were able to obtain more information from their doctors in regard to patient care and gained confidence as a result of these sessions in applying this information to both current and future care. These 
evaluations also helped the clinicians to determine which topics would be useful for future presentations and aided the clinicians in improving teaching techniques.

\section{FUTURE RESEARCH}

Looking to the future, this is a small survey sample that will need further review and trials to determine if it will provide the necessary feedback to help improve small group presentations. It will also need to be spread to other clinical settings to determine if it is beneficial for this style of small groups to aid other learners and to evaluate its helpfulness to interns in putting clinical information and evaluations together for practice. Follow-up studies could also include evaluating students at a later date to determine if the students are using the information that they are learning from the sessions.

This study could be helpful to other medical settings in which students are transitioning from the classroom to the bedside. Allowing small intervals of time for the students to question their instructors' decision-making processes can increase the competence and confidence of the students and further allow the students to make knowledgeable decisions in regard to patient care.

\section{AUTHOR INFORMATION}

Misty Stick-Mueller, D.C. is a 2000 graduate of Palmer College of Chiropractic, Davenport.

She received her Bachelors in Exercise Science from the University of Iowa in 1996 and her Masters Degree in Healthcare Administration in 2008. She began teaching at the collegiate level in 2000 and was in private practice for 4 years as well. She currently is an Assistant Professor of Clinical Science at Palmer where she also serves as an instructor of Legal Issues and Emergency Procedures. She lives in Long Grove, IA with her husband and 3 children.

Ron J. Boesch, D.C. is a 1991 graduate from Palmer College of Chiropractic. He received his Bachelors in Science from Reagent's University of New York. He was in private practice from 1991 through 1999 in Wisconsin and Tennessee. He started his teaching career at Logan College of Chiropractic as a clinical instructor and clinic director. Currently he is the Assistant Director of the Academic Health Center in the Palmer College of Chiropractic's clinic system. He lives in Charlotte, IA with his wife and five children.

Steven L. Silverman, D.C. was born in Philadelphia, Pennsylvania and currently resides in Bettendorf, Iowa. He received his Bachelor and Doctorate degrees from Palmer College of Chiropractic (1995) and is currently completing his Master's in Nutrition through the University of Bridgeport. He was in private practice for 7 years in Pennsylvania and is an Assistant Professor of Clinical Science. In addition to his clinical duties, he also teaches Regulatory Issues at the Davenport, Iowa campus of Palmer College of Chiropractic. He is married and has 2 teenage girls.

Scott A. Carpenter, D.C. is a 1999 graduate of Palmer College. He had a private practice from 2000-2008. He started full time at the college in 2003. He is currently an Assistant Professor and faculty clinician in the Academic Health Center. He works a great deal with extremities and sports related conditions. He currently resides in Bettendorf, Iowa with his daughter.

Robert Illingworth, D.C. currently works at Palmer College of Chiropractic in Davenport, Iowa as a Faculty Clinician in the Academic Health Center since 1994. He graduated from Palmer College in 1992. Dr. Illingworth is currently enrolled in the post-graduate Chiropractic Orthopedics program. He also works seasonal weekends as a Ski Instructor at Chestnut Mountain Resort in Galena, Illinois. He lives in Bettendorf, Iowa.

James Countryman D.C. is a 1985 graduate of Palmer College of Chiropractic in Davenport, Iowa. He is currently a faculty clinician in the Academic Health Center at Palmer College where he has worked for the past 20 years. Dr Countryman is certified as proficient in advanced SOT and has a certificate in Craniopathy. 


\section{REFERENCES}

1. Conley, K. (2001). An Investigation of the Dimensions of Mentoring. University of Kansas. Retrieved online August 27, 2009 from the EBSCOhost database.

2. Kim, S. (2007). Learning Goal Orientation, Formal Mentoring, and Leadership Competence in HRD: A Conceptual Model. Journal of European Industrial Training, 31(3). Retrieved online August 27, 2009 from the EBSCOhost database.

3. Marx, E. (2006). Mentor Programs Help Create Leaders of Tomorrow. Health Care Strategic Management, 24(12), 10-11. Retrieved online August 27, 2009 from the EBSCOhost database. 


\section{NOTES}

